\title{
DEPENDÊNCIA TECNOLÓGICA EM IDADE ESCOLAR
}

Letícia Rodrigues Braga ${ }^{1}$ Arthur Siqueira de Sene ${ }^{2}$

INTRODUÇÃO: A adaptação ao ambiente é uma das características fundamentais do ser humano em sociedade. Um dos métodos exponenciais que podem facilitar esse processo adaptativo são os desenvolvimentos tecnológicos em diversas áreas da vida. Contudo, o grande avanço tecnológico permite também o acesso às tecnologias contemporâneas de maneira ampla e irrestrita, tornando possível uma maior interação e necessidade do indivíduo em estar conectado. $\mathrm{O}$ 'estar conectado' é continuamente corroborado por estratégias criadas, especialmente pelas mídias diversas, pela própria sociedade, que entende como necessário e urgente a utilização contínua da tecnologia na inserção e socialização do indivíduo. Um dos reflexos desse uso contínuo e, por vezes descontrolado, é o desenvolvimento da dependência da tecnologia, o que gera prejuízos no funcionamento de diversas áreas da vida do usuário. Adolescentes, da geração $Z$, adquiriram uma relação natural com o meio tecnológico, devido à grande inserção das novas tecnologias utilizadas no cotidiano. A grande maioria, criou vínculos e conceitos de que os bens tecnológicos são insubstituíveis e necessários, uma vez que, essa geração consegue fazer o uso de aparelhos eletrônicos sem dificuldades, por diferentes formas e com intuitos variados. Diante disso, eles são constantemente expostos a esse novo fenômeno, tentando cada vez mais acompanhar as mudanças e sendo afetados com os efeitos dessa exposição. Grande parte deles utilizam algum aparato tecnológico como sendo a principal e indispensável atividade de lazer. OBJETIVO: A velocidade de transformação das relações e interações sociais, baseados em artefatos tecnológicos, tem gerado novos padrões de comportamentos. Frente a esses novos comportamentos, a proposta deste trabalho, é investigar para qual finalidade a tecnologia está sendo utilizada e quais os mecanismos podem influenciar no comportamento do adolescente em idade escolar. METODOLOGIA: A presente pesquisa foi realizada por meio de uma revisão seletiva da literatura, de natureza qualitativa e descritiva, de artigos, teses e livros que fossem publicados, prioritariamente, em língua portuguesa, no período de 2007 a 2017. Abordando a temática

\footnotetext{
${ }^{1}$ Acadêmica do curso de psicologia da Faculdade Patos de Minas - FPM. E-mail: leticia_braga2008@hotmail.com

2 Docente do departamento de psicologia da Faculdade Patos de Minas - FPM.
} 

da influência tecnológica sobre o comportamento de adolescentes em idade escolar. RESULTADOS E CONSIDERAÇÕES FINAIS: A internet exerce um papel influente no cotidiano dos adolescentes, em especial, no que se refere a Geração Z, que é composta por indivíduos que dão grande importância ao mundo virtual. Percebe-se que é necessário ofertar possibilidades, através da utilização da tecnologia, por parte dos mediadores, para que busquem orientar seus alunos acerca dos pontos negativos e positivos que o meio tecnológico disponibiliza. A fim de minimizar as dependências e problemas causados por ela, agregando seus recursos ao aprendizado. Promovendo aprendizado e comportamentos que vão oferecer maiores benefícios e menos risco à dependência. No entanto, explorar as oportunidades oferecidas pela tecnologia, desenvolvendo novas práticas de ensino e aceitando-a como uma ferramenta facilitadora, torna-se um desafio, porém, proporciona mudanças no intuito de melhorar o ensino e orientar os adolescentes.

Palavras-chave: Adolescente; Dependência tecnológica; Educação: Geração Z. 